\title{
Competition and the Number of Firms in a Market: Are Duopolies More Competitive than Atomistic Markets?
}

\section{Joseph E. Stiglitz}

Princeton University

\begin{abstract}
This paper uses a variant of the standard search model to examine market equilibrium and the consequences for market equilibrium of an increase in the number of firms. If marginal search costs increase with the number of searches, then the demand curve facing any firm will be kinked, with the elasticity of demand with respect to price decreases being less than with respect to price increases; prices may not change in response to changes in marginal costs. As the number of firms increases, the maximum price that is consistent with equilibrium increases, to the monopoly price, but the minimum price decreases. On the other hand, if marginal search costs decrease with the number of searches, equilibrium, if it exists, is characterized by a price distribution.
\end{abstract}

How many firms are needed to make a market function competitively? If there is perfect information, two firms that behave like Bertrand competitors will drive the price to marginal cost. ${ }^{1}$ In contrast, in a Cournot equilibrium, as the number of firms increases, the perceived elasticity of demand increases, and price falls; the competitive price is attained only in the limit.

This research was supported by the National Science Foundation grant SES-8320464 at the Institute for Mathematical Studies in the Social Sciences, Stanford University, Stanford, California, partially by the Hoover Institution, and partially by a National Science Foundation grant to Princeton. I have benefited from discussions over the years on the topic of this paper with Steve Salop and Michael Rothschild and from helpful comments on an earlier draft by Peter Crampton, José Scheinkman, Bernard Salanie, and Arunava Sen.

${ }^{1}$ Assuming there are no capacity constraints. 
Though it has long been recognized that imperfect information would make markets act less competitively (Scitovsky 1950; Salop 1976), modern search theory has raised serious questions concerning the robustness of even the qualitative result that increasing the number of firms should lead to lower prices. Although the nature of market equilibrium with a finite number of firms has not been extensively studied, the case in which there is an infinite number of firms has been. If individuals search sequentially and there are finite search costs (no matter how small), then the market equilibrium is the monopoly price. Two other striking results have been obtained: (1) there cannot exist an equilibrium price distribution (see Diamond 1971); and (2) if there is a fixed cost associated with the first search, equilibrium will not exist if (see Stiglitz 1979; Salop and Stiglitz 1982) (a) firms can use nonlinear price schedules or $(b)$ individuals have a utility function that leads them to buy one unit if the price is below some reservation price level.

Search costs, even small search costs, have an enormous effect on the nature of the equilibrium. ${ }^{2}$

The objective of this paper is to consider the consequence of three seemingly minor modifications of the standard sequential search model: (1) There are some individuals with infinitesimal search costs. If $F(s)$ is the distribution function of individuals by search costs, $s$, and $f(s)$ is the density, then $f(0)>0 .^{3}(2)$ There are a finite number of firms rather than an infinite number of firms. (3) The cost of sampling an additional firm may depend on the number of firms already sampled.

If there are a finite number of firms, the equilibrium price is below the monopoly price: duopoly appears to be more competitive than atomistic competition. The reason for this is that, in the atomistic models that have been studied, if a firm lowers its price, it will not induce search, whereas in a duopoly, it will. Thus the perceived price elasticity with duopoly is greater than in atomistic competition. As the number of firms increases, the cost of finding a low-price store increases. Hence, the amount of induced search is reduced. Increasing the number of firms seems to have an anticompetitive effect.

As the number of firms increases, however, there are two effects: if a firm lowers its price, only those with relatively low search costs will find it worthwhile to search since it is harder to find this "bargain."

\footnotetext{
${ }^{2}$ For a survey of these results, see Stiglitz (1979). See also Axell (1977) and von zur Muehlen (1980).

${ }^{3}$ Braverman (1980) and Braverman and Dixit (1981) have investigated the consequences of $f(0)>0$ in the slightly different context of the Salop and Stiglitz (1977) model of search.
} 
But while a smaller percentage of individuals at any store are induced to search, there are more stores from which customers can be attracted. When search costs are constant and there is search with replacement, ${ }^{4}$ the second effect is shown to dominate the first: The conventional result that increasing the number of firms increases the effective degree of competitiveness in the market is reestablished. In the limit, as the number of stores increases to infinity, the price decreases monotonically from the monopoly price to a price that is lower by an amount that depends on $f(0)$, provided only that $f(0)>0 .^{5}$

Thus the standard characterization of the equilibrium with a continuum of firms as entailing the monopoly price is not correct if $f(0)$ $>0$.

Standard expositions, while focusing on the first effect, have failed to note the importance of the second effect. Thus, as the number of firms increases, the store that lowers its price recruits very few customers from each of a very large number of stores. It is not correct simply to assume that the number recruited from any one store goes to zero faster than the number of stores increases.

Standard expositions have made a second, important error: they have failed to note the asymmetry of information that is created in these markets the moment an individual arrives at a store. He knows the price at that store; he knows only the distribution of prices at other stores. This asymmetry of information has an important consequence: the elasticity of demand with respect to price increases may differ markedly from the elasticity of demand with respect to price decreases. Demand curves in general will be kinked. This in turn has two consequences: (1) If there are a finite number of firms, marginal search costs are constant, and search is conducted without replacement, then the only equilibria entail price distributions; this result holds more generally with decreasing marginal search costs. This result generalizes the analysis of Salop and Stiglitz (1977), who employed the limiting case of a convex search technology in which all searches after the first were, in effect, free. (2) If there are increasing marginal search costs, there may be an indeterminacy of equilibria, and output may not change when marginal costs change.

There are two reasons why it is important to investigate models that generate price distributions. First, there is considerable evidence that product markets are frequently characterized by essentially identical commodities being sold at markedly different prices, ${ }^{6}$ and a model of

\footnotetext{
${ }^{4}$ Search without replacement means that if an individual samples a store and rejects it, he will not return to it.

${ }^{5}$ In the limiting case in which $f(0)=0$, there is a critical number of firms, $N$, below which there is no single price equilibrium (see Arrow and Rothschild 1973).

${ }^{6}$ Those who believe in the law of the single price may claim that the products sold at
} 
the product market should at least admit this as a possible outcome. ${ }^{7}$ Second, I noted earlier that, under plausible conditions, if the first search is costly, there exists no equilibrium in the market. This seeming paradox is resolved if there is at least some probability that the price charged is below the monopoly price. Thus the models we have constructed have an internal consistency that was lacking from the models of product markets in which all consumers have strictly positive search costs and there is a continuum of firms. ${ }^{8}$

This paper is divided into four sections. The model is presented in Section I, while Section II presents the results for a finite number of firms and linear search cost technology. Section III shows how the analysis is altered with a nonlinear search cost technology. Section IV considers the robustness of the results.

\section{The Model}

Let us consider a market in which, for simplicity, all individuals have identical demand functions for the given commodity, $x=x(p)$, but they differ in their search costs. The individual's indirect utility function can be written as

$$
U=v(p)+Y,
$$

where $Y$ is the individual's income. Thus, by Roy's formula,

$$
x=-v^{\prime} .
$$

Individuals have a simple search rule: purchase if, on the $t$ th search, $p \leq \hat{p}_{t}$; do not if $p>\hat{p}_{t}$. The term $\hat{p}_{t}$ is the reservation price for the $t$ th search. It is the price such that the utility an individual obtains from purchasing at the store he is at presently is equal to the expected

different prices differ in some important way, e.g., location, service, etc. This may be true in some instances, but in other instances the magnitude of the price differences is sufficiently large to suggest that these "quality" differences cannot fully account for the observed price differences. In those cases in which these quality differences are important, the appropriate model for analyzing the market is a differentiated commodity market with search costs; such markets will, in general, be characterized by price distributions in the natural sense that, even if the technologies with which the goods are produced are identical, they will sell for different prices.

${ }^{7}$ Indeed, this was one of Rothschild's (1973) most salient criticisms of Stigler's (1961) model: given Stigler's assumptions concerning consumer behavior, all firms would charge the same price.

${ }^{8}$ Formally, we can avoid these nonexistence difficulties in the standard way by assuming that the first search is free (see Sec. I). But this is clearly an unsatisfactory assumption. If we assume that the first search costs the same as subsequent searches, our analysis will essentially be unaffected provided the average equilibrium price is low enough; i.e., $f(0)$ is high enough. (Otherwise, we would again encounter problems of existence.) 
utility he obtains from continuing search. How the expected utility from continuing search is calculated depends on the nature of the search process, for example, whether search is with or without replacement. ${ }^{9}$

Assume that in this market there are $L$ individuals and $N$ firms. ${ }^{10}$ All individuals know the probability distribution of prices, but not which store charges which price. ${ }^{11}$ Customers randomly search among firms. Each individual continues to search until he finds a store that charges a price at or below his reservation price.

Denote by $s_{t}$ the cost of the $t$ th search. The literature has focused on three special cases: (a) Linear search cost technologies for which $s_{t}=\bar{s}$, a constant, for $t>1$. Because equilibrium may not exist if $s_{1}>0$, I assume $s_{1}=0$. (b) Convex search technologies. The scarcity of time (and other resources) means that search costs may increase with the number of searches: $s_{t} \geq s_{t-1}$ for all $t$. A special case of this (used, e.g., in Salop and Stiglitz [1982]) entails fixed search costs up to some $t$ and infinite search costs beyond that. (c) Concave search technologies. If stores are clustered around a shopping area, then most of the costs associated with shopping may be the fixed costs of going to the shopping center. Similarly, if individuals obtain information by purchasing, say, a consumer report, they are likely to obtain information about several stores simultaneously. These are all cases in which the marginal cost of search is less than the average, that is, $s_{t} \leq s_{t-1}$ for all $t$. The limiting case of this, explored by Salop and Stiglitz (1977), is that in which $s_{1}>0, s_{t}=0$ for $t>1$.

Individuals differ in their search costs. In the case of linear search technology, we can represent this by the distribution function $F(s)$.

We can represent the revenue of the firm by

$$
R=M p x
$$

where $M$ is the number of customers who purchase; $M$ is a function of the price charged by the given firm as well as prices charged by other firms.

The marginal cost of the product is $c$. Thus the profit-maximizing

\footnotetext{
${ }^{9}$ In either case, under the assumption of constant search costs, if it pays the individual to continue searching when he samples a price $p$ today, it pays him to continue searching if he subsequently samples the same price at another store.

${ }^{10}$ Throughout the analysis, the number of firms will be exogenously determined. But it is easy to allow the endogenous determination of $N$, as in Salop and Stiglitz (1977), with $U$-shaped average cost curves for firms.

${ }^{11}$ This is a standard assumption in this literature. Though there are some circumstances in which it may have some validity, its main justification is that it greatly simplifies the analysis.
} 
firm sets marginal revenue equal to marginal cost, or

$$
p=\frac{c}{1-(1 / \epsilon)},
$$

where $\epsilon$ is the elasticity of the demand curve facing the firm:

$$
\epsilon \equiv-\frac{d \ln M}{d \ln p}+E\left(p^{*}\right)
$$

where $E$ is the elasticity of the individual demand curves,

$$
E(p) \equiv-x^{\prime}(p) \frac{p}{x}
$$

Note that, for a monopolist, $d \ln M / d \ln p=0$, so $\epsilon=E\left(p^{*}\right)$. We can denote the monopoly price by $p^{m}$ :

$$
p^{m}=\frac{c}{1-\left[1 / E\left(p^{m}\right)\right]} .
$$

When $M$, the number of customers, is not a differentiable function of $p$, we denote by $\epsilon^{+}$and $\epsilon^{-}$the elasticity with respect to price increases and decreases.

If $\epsilon^{+}\left(p^{*}\right)>\epsilon^{-}\left(p^{*}\right)$, as in figure 1 , the demand curve has a kink at $p=p^{*}$, and prices will not, as a result, respond to changes in marginal costs as long as

$$
\frac{c}{1-\left[1 / \epsilon^{+}\left(p^{*}\right)\right]}<p^{*}<\frac{c}{1-\left[1 / \epsilon^{-}\left(p^{*}\right)\right]} .
$$

Much of the remainder of the paper is devoted to ascertaining how the number of customers changes with changes in $p$; that is, is $M$ differentiable and what is the value of $\epsilon^{+}$and $\epsilon^{-}$?

\section{Symmetric Equilibrium with a Finite Number of Firms, $f(0)>0$, and Linear Search Technology}

When there are a finite number of firms, it makes a difference whether search is with or without replacement. ${ }^{12}$ In the first two parts of this section, we will consider only the symmetric equilibrium. With linear search costs, the reservation price, $\hat{p}_{t}$, is a constant for all $t$ and is denoted by $\hat{p}$.

\footnotetext{
${ }^{12}$ Which is more plausible depends on the memory of searchers and on whether firms are pursuing mixed strategies. This will be discussed later.
} 


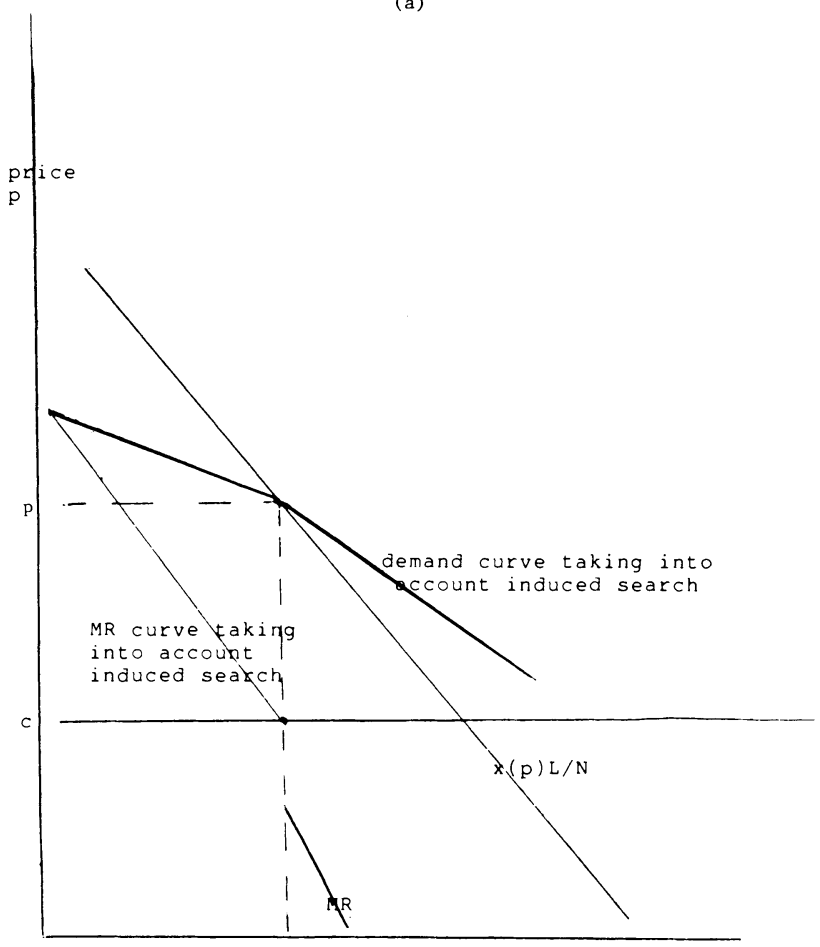

(b)

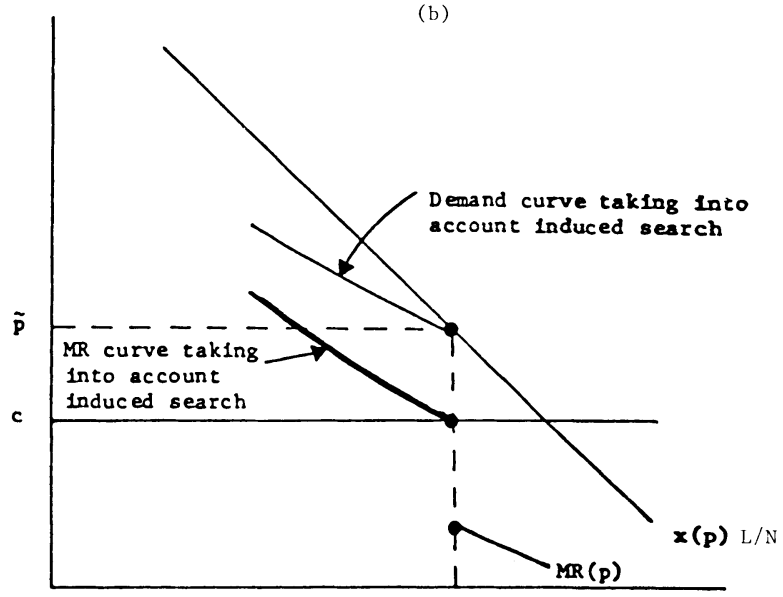

Fig. 1.-a, Kinked demand curve. $b$, Equilibrium with a continuum of firms and $f(0)$ $>0$ : the equilibrium is indeterminate; the price must be less than or equal to the monopoly price but greater than or equal to $\tilde{p}$. 


\section{A. Search without Replacement}

Consider a market with $N$ firms, all charging a price $p=p^{*}$. In equilibrium, each sells to $L / N$ customers. One firm contemplates raising its price to $p>p^{*}$. Its low-search-cost customers will leave. Customers know for certain that on the next search they will find a lowprice store. Hence, all those with search costs less than $\hat{s}$ leave, where $\hat{s}$ is defined by

$$
v\left(p^{*}\right)-v(p)=\hat{s}(p) .
$$

Equation (8) tells us how many individuals will be searching: all those with $s<\hat{s}$. The function $F(\hat{s}(p))$ gives the fraction of individuals who search at each value of $p$. Using equation (2), we get

$$
\frac{d \hat{s}}{d p}=-v^{\prime}(p)=x(p)
$$

The store that raises its price thus finds that it sells only to

$$
M=\frac{L}{N}[1-F(\hat{s}(p))]
$$

customers. Differentiating (10), we see that the elasticity of demand at $p=p^{*}$ is

$$
\epsilon^{+}\left(p^{*}\right)=E\left(p^{*}\right)+f(0) x\left(p^{*}\right) p^{*}
$$

A firm that contemplates lowering its price below $p^{*}$ knows that it will attract the lowest-search-cost individuals from all other stores while retaining all the high-search-cost people who happen by chance to arrive at its doorstep. Its expected number of customers will be

$$
L\left[F(\hat{s}(p))+\frac{1-F(\hat{s}(p))}{N}\right],
$$

where $\hat{s}(p)$ is the critical search cost (a function of the price charged by the low-price store) such that all individuals with $s \leq \hat{s}$ search until they find the low-price store.

The expected number of searches to find the single low-price store (if an individual arrives at a high-price store) is $N / 2$; hence $\hat{s}$ is given by

$$
v(p)-v\left(p^{*}\right)=\hat{s}(p) \frac{N}{2} .
$$

It immediately follows that the demand elasticity with respect to price decreases is

$$
\epsilon^{-}\left(p^{*}\right)=E\left(p^{*}\right)+\frac{2(N-1)}{N} f(0) p^{*} x\left(p^{*}\right) \geq \epsilon^{+}\left(p^{*}\right),
$$




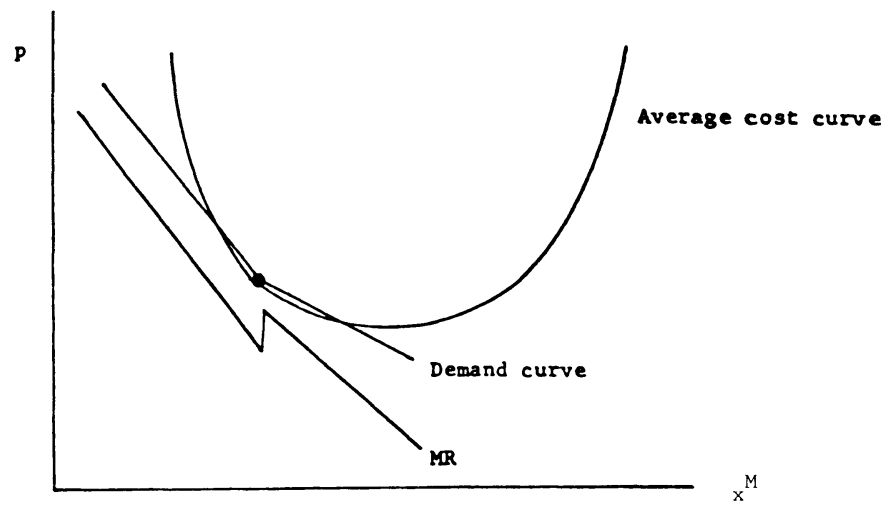

Fig. 2.-With three stores and search without replacement there is a kink at $p^{*}$ so that there cannot exist a single price equilibrium.

with equality holding only for $N=2$. Thus, if there are more than two firms, there is a kink in the demand curve, with the elasticity of demand for price decreases exceeding that for price increases. This immediately implies that for $N>2$ there cannot be a single price equilibrium (see fig. 2).

\section{B. Search with Replacement}

The analysis is identical to that given before except now, if a single firm raises its price, it will take an individual who happens to arrive at the high-price store, on average, $N /(N-1)$ searches to find a lowprice store. However, if a single firm lowers its price, it will take $N$ searches, on average, for an individual who first arrives at a highprice store (one charging $p^{*}$ ) to find the low-price store. Modifying equation (13), determining the marginal individual who searches in the appropriate way, we can immediately calculate the elasticity of demand for price increases and price decreases:

$$
\epsilon^{+}=\epsilon^{-}=\epsilon=E+f(0) p x \frac{N-1}{N} .
$$

Now there is no kink in the demand curve; there exists a single price equilibrium, and the price is below the monopoly price. Moreover, as the number of firms increases, the market price falls monotonically. ${ }^{13}$

${ }^{13}$ This result stands in marked contrast to that of Satterthwaite (1979), who argued that as the number of firms increases the degree of imperfection of information increases. This reduces the demand elasticity and hence increases the market equilibrium price (see also Pauly and Satterthwaite 1981). His model differs in two crucial ways from the one presented here: $(a)$ He was concerned with heterogeneous goods, with 
In the limit, the price is less than the monopoly price, $p^{m}$ :

$$
p=\tilde{p}=\frac{c}{1-(1 / \tilde{\epsilon})}<\frac{c}{1-\left[1 / E\left(p^{m}\right)\right]}=p^{m},
$$

where

$$
\tilde{\boldsymbol{\epsilon}}=E(\tilde{p})+f(0) \tilde{p} x(\tilde{p}) .
$$

\section{Equilibrium Price Distributions}

When there is search without replacement, there never exists a single price equilibrium; the only equilibria are those in which different stores charge different prices. But even when there exists a single price equilibrium, there may exist other equilibria, with different stores charging different prices. ${ }^{14}$ Since each firm will perceive an elasticity of demand that exceeds $E$ (i.e., if it raises its price, it loses some customers; if it lowers its price, it gains some), all prices within the equilibrium price distribution are lower than the monopoly price. I present an example in Appendix A in which there are three stores, two charging a high price and one a low price. ${ }^{15}$

The example constructed in Appendix A is consistent with $f(0)=$ 0 . Thus the result that with finite search costs the only equilibrium entails a single price depends critically on there being an infinite number of firms. If there is a finite number of firms, when the lowestprice firm increases its price, some individuals who are at higher-price stores and presently search will no longer find it worth their while to

characteristics that were valued differently by different individuals; we have a homogeneous good. (b) His information acquisition technology is markedly different from the one employed here. He assumed that individuals obtain information about qualities via a reputation mechanism, not by search. Although his model is consistent with a number of alternative assumptions concerning what information individuals have about prices and how they acquire more information, it is not consistent with the sequential search model posited here. Salop (1979) and Salop and Stiglitz (1987) have previously noted that improved information may either increase or decrease the elasticity of demand. Thus it should not come as a surprise that different assumptions generate such markedly different results. Rosenthal $(1980,1982)$ has presented a rather different model in which an increase in the number of sellers leads to a higher price.

${ }^{14}$ The fact that all stores have the same technology does not mean that the only equilibrium entails all stores charging the same prices (cf. Butters 1977; Salop and Stiglitz 1977, 1982; Satterthwaite 1979; Stiglitz 1985). By contrast, it is easy to construct models with price distributions when technologies differ (see, e.g., Reinganum 1979).

${ }^{15}$ There are, as usual, two interpretations to equilibrium price distributions. One entails mixed strategies, while in the other, some stores are always high-price stores, others low-price stores. The former has the advantage that the hypothesis that individuals know the price distribution but not which store charges which price is more plausible than in the latter. The appropriate search model in that case entails search with replacement if the period of search and the period during which prices at a store are fixed coincide. 
do so. The property that the number of customers is unaffected by small price changes is essential to the result that the only equilibrium entails a single price.

\section{Continuum of Firms}

When there is a continuum of firms, all prices charged must yield the same profit; each firm is sufficiently small that it believes it will have no effect on search behavior, and hence if, at some price, profits exceeded those at other prices, all firms would switch their price to the one that generates the higher level of profits. Any particular price distribution will generate a particular search behavior (reservation prices for individuals with different search costs); this will determine the sales at each price and, hence, the profitability at each price. The question is, Does there exist a nondegenerate price distribution such that profits are the same at each level of prices charged? In Appendix $\mathrm{B}$, I show that there may be; I derive the differential equation that the price distribution must satisfy and present an example. I also show that the maximum price of the distribution is below the monopoly price.

\section{More General Search Technologies}

The results obtained in Section II, though striking, are somewhat special. They depend on the special nature of the search technology. It was assumed that, though individuals differed in their search costs, the costs of making each search were independent of the number of searches. This assumption is crucial but implausible. On the one hand, many of the costs of search are fixed: once one has arrived at a shopping center, the marginal costs of going to an additional store may be relatively small. On the other hand, beyond some point, there are increasing costs associated with search: time and money become increasingly scarce. While the former effect makes it more likely that there will not be a single price equilibrium, the latter effect may lead to a kinked demand curve of the form of figure 1 and to the price increasing with the number of firms in the market. When there are many firms in the market, there is a considerable chance that it may take a number of searches to find the low-price store; thus the expected cost of finding the low-price firm may increase faster than $N$. This will lower the price elasticity for price decreases, giving rise to a kink. And the larger the number of firms, the less elastic the demand curve, thus giving rise to the possibility that prices increase with the number of firms. 
Rather than establishing these results in general, we will derive them for the two limiting cases noted earlier.

\section{A. Convex Search Costs}

Assume that at most two searches are feasible:

$$
s_{1}=0, s_{2}=s, s_{t}=\infty \text { for } t>2 .
$$

Now it makes a difference whether a customer who has sampled a store and left can return without incurring a search cost. For simplicity, assume not.

\section{Search without Replacement}

The value of $\epsilon^{+}$is unchanged, but now an individual at a high-price store will set out to find the low-price store if and only if

$$
\frac{v(p)-v\left(p^{*}\right)}{N-1} \geq \hat{s} .
$$

Of those searching, only $1 /(N-1)$ find the low-price store, so

$$
M=L\left[\frac{F(\hat{s})}{N-1}\left(\frac{N-1}{N}\right)+\frac{1}{N}\right] .
$$

Hence

$$
\epsilon^{-}=E\left(p^{*}\right)+\frac{f(0) p^{*} x\left(p^{*}\right)}{N-1} .
$$

As $N$ increases, this decreases. The demand curve has a kink of the form of figure 3 for $N>2$. As $N \rightarrow \infty$, the range of indeterminacy of price increases, with $\tilde{p} \leq p \leq p^{m}$; the price may be anywhere between the monopoly price and $\tilde{p}$, where $\tilde{p}$ is defined by equation (15). Since $\epsilon^{-}$is decreasing, it is apparent that, as $N$ increases, the market price could increase.

2. Search with Replacement

Straightforward calculations establish that

$$
\begin{gathered}
\boldsymbol{\epsilon}^{-}=E\left(p^{*}\right)+f x p^{*} \frac{N-1}{N^{2}}, \\
\boldsymbol{\epsilon}^{+}=E\left(p^{*}\right)+f x p^{*}\left(\frac{N-1}{N}\right)^{2} .
\end{gathered}
$$




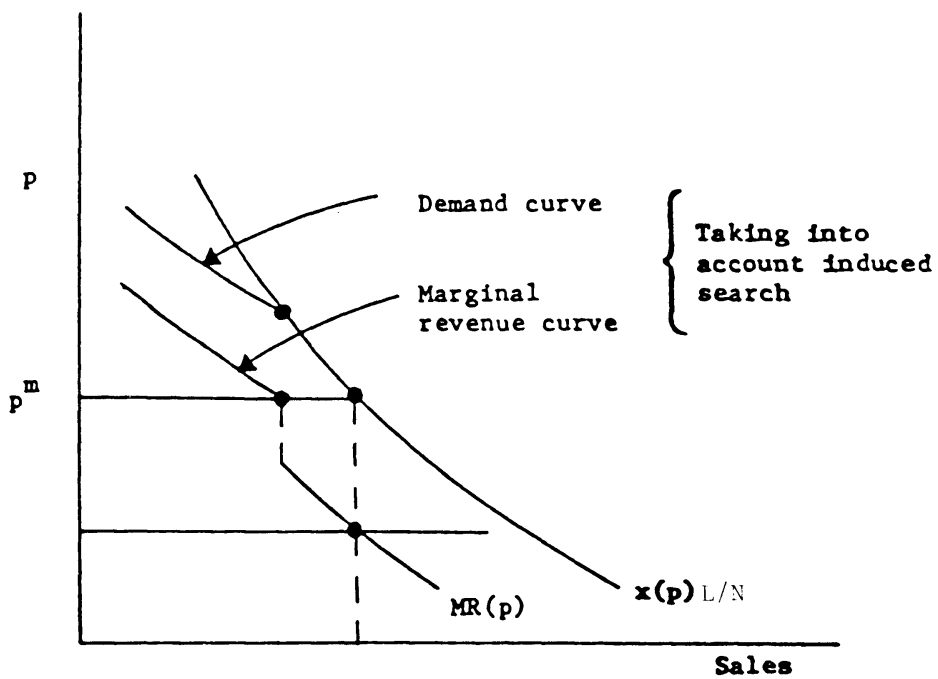

Fig. 3.-If $f(0)=0$, there is no kink at $p=p^{m}=p^{*}$, and the only equilibrium is the monopoly price.

Again, a kink appears if $N>2: \epsilon^{+}>\epsilon^{-}$for $N>2$. And as $N$ increases, $\epsilon^{+}$increases while $\epsilon^{-}$decreases, with $p$ being between $\tilde{p}$ and $p^{m}$, in the limit, as $N$ goes to infinity.

\section{B. Concave Search Costs}

Assume now that $s_{1}=s_{2}>0$ and $s_{t}=0$ for $t>2$. Now if an individual searches after arriving at a store (i.e., if he goes to more than one store), he becomes perfectly informed. Hence, it makes no difference whether search is with or without replacement; the search condition for price increases is again (8), so $\epsilon^{+}$is still described by (11).

The search condition for price decreases, however, is now also described by (8) and expected sales by (12). Hence

$$
\boldsymbol{\epsilon}^{-}=E\left(p^{*}\right)+f(0) x p^{*}(N-1) \geq \boldsymbol{\epsilon}^{+},
$$

with strict inequality holding for $N>2$ : If there are more than two firms, then there does not exist a single price equilibrium.

\section{Robustness of the Results}

This paper has shown that the one model of sequential search that has been extensively investigated in the literature, the one in which there are strictly positive search costs and a continuum of firms, is indeed 
special. I have argued that the results of that model, that the unique equilibrium entails a single price at the monopoly level, are not robust. In contrast, I believe that my results (i.e., that prices may be below the monopoly level and there may exist a price distribution) are robust. It is the absence of the extensive margin that results in the monopoly price being the market equilibrium price with strictly positive search costs and a continuum of firms. The general case, which is depicted in this paper, is the one in which there is an extensive margin. When there is an extensive margin, the highest price will be lower than the monopoly price. For instance, in markets with differentiated commodities or in markets in which individuals are imperfectly informed concerning the price distribution and have (as would be expected) different priors concerning it, when firms lower their prices, they not only will sell more to each customer but will find that there are more customers willing to purchase.

In general, I have noted that the elasticity of demand with respect to price increases and with respect to price decreases will not be the same. With concave search technologies or linear search technologies with search without replacement, we obtain the result that in equilibrium there must be a price distribution. This is consistent with the kinds of results obtained earlier by Salop and Stiglitz (1977). With convex search technologies, we obtain a kinked demand curve. It is important to note that the kinked demand curve arises in a competitive model, not from the oligopolistic interactions that are central to the traditional kinked demand curve.

\section{Conclusions}

It is surprising that, in spite of the long recognition of the importance of search costs, the full implications for the nature of market equilibrium have, until now, been so little investigated.

There were two primary motivations for undertaking the analysis of this paper. The first was to investigate whether the standard presumption that competition was more effective the larger the number of firms was valid within a search model. The results concerning the relationship between the number of firms and the equilibrium price turned out to be less clear-cut than I had hoped. The conventional result was established for the linear search cost technology. With a concave search cost technology, there was not an equilibrium price, only an equilibrium price distribution; however, with a convex search cost technology, as the number of firms increased, there was an increasingly large indeterminacy in the equilibrium price. While the minimum value of the range decreased, the maximum value in- 
creased: in the limit, the maximum price was in fact the monopoly price. $^{16}$

The second motivation for this study was to ascertain the conditions under which markets in which search was important would be characterized by firms facing kinked demand curves, which would give rise to the kinds of rigidities commonly associated with macroeconomic rigidities. I have shown that this is in fact the case, provided only that the search cost technology is convex. As a result, changes in, say, wages may not result in any alteration, either in output or in price. The location of the kink depends on individuals' beliefs about what different stores are doing (or, more accurately, since what is relevant is the store's perception of the demand curve it faces, the location of the kink depends on the store's beliefs about individuals' beliefs about the price distribution). Thus, if all (stores believe all) individuals believe that all (other) stores have raised their prices by 5 percent, then the price at the kinked output will move up by 5 percent. The model is thus consistent with either nominal or real price rigidities. There are multiple equilibria. I have not, of course, provided a theory of how (a store's expectations of) individuals' expectations get formed, of how, in other words, certain conventions get established. If, for instance, the costs of inputs of different firms are highly correlated and all firms in the past have passed on cost increases but not cost decreases, then in fact the price at the kink will rise with a rise in the cost of inputs but will not fall with a fall in these costs.

Though the theory may have greater applicability for consumer goods markets than for other markets, note that, with differentiated commodities, the derived demand facing a manufacturer may itself have a kink reflecting the kink in the underlying demand curves facing its retailers.

The models formulated in this paper have been basically static. Individuals search for and purchase consumption for only one period. In many cases, once individuals decide to purchase at a store, they remain customers at that store for an extended period of time. To dislodge "loyal" customers from other stores by price cutting is difficult, suggesting that the elasticity of demand with respect to price

\footnotetext{
${ }^{16}$ By contrast, Satterthwaite (1979) obtained an unambiguous result. In addition to the differences between this model and that of Satterthwaite noted in n. 13 above, one other important difference should be emphasized. In this model, firms explicitly take into account the fact that, by lowering their prices, some low-search-cost individuals who otherwise would not have searched are induced to do so. Satterthwaite ignores this effect. Since this induced search effect would seem to be strongest when there are few firms, I had originally thought that the presumption that prices are positively related to the number of firms would be even stronger than in Satterthwaite's model.
} 
decreases may be low. This exacerbates the rigidity-inducing kink analyzed in this paper. Unfortunately, the formal analysis of such a dynamic model would take us beyond the scope of this brief paper.

\section{Appendix A}

\section{Multiple Price Equilibria: An Example}

I illustrate multiple price equilibria in which two stores charge the high price $p_{1}$ and one store charges the low price $p_{2}$, with a fraction $F(\hat{s})$ of those who arrive at a higher-price store searching, where

$$
v\left(p_{2}\right)-v\left(p_{1}\right)=\frac{3 \hat{s}}{2}
$$

(since it takes, on average, $3 / 2$ searches to find a low-price store, assuming search without replacement). Sales at a high-price store are $[1-F(\hat{s})] / 3$ and at the low-price store are $[1+2 F(\hat{s})] / 3$.

If one of the high-price stores raises its price by $\Delta$, it loses some customers. Anyone who leaves the highest-price store (charging $p_{1}+\Delta$ ) will continue to search until he finds the lowest-price store; for if it pays someone to search with a $50 / 50$ chance of saving $\Delta$ or $p_{1}+\Delta-p_{2}$, it surely pays him to search if there is a probability one of saving $p_{1}+\Delta-p_{2}$ (per unit purchased). Hence, such an individual searches if $s<\hat{\hat{s}}$, where

$$
\frac{3 \hat{s}}{2}=v\left(p_{2}\right)-v\left(p_{1}+\Delta\right) .
$$

If the firm lowers its price, by the same reasoning any individual who is willing to search from the highest-price firm to the second is willing to search to the lowest-price firm. Hence, its sales are still $[1-F(\hat{s})] / 3$, with

$$
\frac{3 \hat{s}}{2}=v\left(p_{2}\right)-v\left(p_{1}+\Delta\right) .
$$

Thus the demand elasticity is

$$
E+\frac{2 f(\hat{s}) x p}{3[1-F(\hat{s})]}
$$

and

$$
\frac{p_{1}-c}{p_{1}}=1 /\left\{E+\frac{2 f(\hat{s}) x_{1} p_{1}}{3[1-F(\hat{s})]}\right\},
$$

where $x_{1}=x\left(p_{1}\right)$. Similar calculations establish that the demand elasticity at the low-price store is

$$
E+\frac{4 f(\hat{s}) x p}{3[1+2 F(\hat{s})]}
$$


So letting $x_{2} \equiv x\left(p_{2}\right)$, we get $^{17}$

$$
\frac{p_{2}-c}{p_{2}}=1 /\left\{E+\frac{4 f(\hat{s}) x_{2} p_{2}}{3[1+2 F(\hat{s})]}\right\} .
$$

Assume constant elasticity demand curves. If $p_{1}>p_{2}$,

$$
\frac{2 x_{2} p_{2}}{1+2 F(\hat{s})}>\frac{x_{1} p_{1}}{1-F(\hat{s})}
$$

or

$$
F(\hat{s})<\frac{2\left(p_{2} / p_{1}\right)^{1-E}-1}{2\left[1+\left(p_{2} / p_{1}\right)^{1-E_{1}}\right]} .
$$

If $E=1$, this is satisfied if $F(\hat{s})<1 / 4$. Comparing (14) and (Al), we see that

$$
p_{1} \lessgtr p^{*} \text { as } \frac{2 f(s) x_{1} p_{1}}{3[1-F(\hat{s})]} \gtrless f(0) x^{*} p^{*},
$$

while from (14) and (A2),

$$
p_{2} \lessgtr p^{*} \text { as } \frac{4}{3} \frac{f(\hat{s}) x_{2} p_{2}}{1+2 F(\hat{s})} \gtrless f(0) x^{*} p^{*} .
$$

For instance, if $E=1, F(\hat{s})<1 / 4$, and $f(0)<8 / 9 f(\hat{s}), p_{2}<p_{1}<p^{*}$ : both prices are lower than the symmetric duopoly price. It is apparent that the reverse inequalities can hold with other distributions of search costs. Similarly, if $E=1, F(\hat{s})<1 / 4$, and $f(0)<f(\hat{s})$, both prices are lower than the symmetric three-firm equilibrium (where there is search with replacement).

\section{Appendix B}

\section{Equilibrium Price Distribution with a Continuum of Firms}

Let us focus on the limiting case in which production costs are zero and all individuals purchase one unit, provided price is less than $u$. If $G(p)$ is the price distribution, recall that the reservation price for an individual with search costs $s$ is given by

$$
\hat{p}=\hat{p}(s)=\frac{\int_{0}^{\hat{p}} p d G(p)}{G(\hat{p})}+\frac{s}{G(\hat{p})} .
$$

Those with search costs $s$ will allocate themselves evenly among all the lowerprice stores; that is, each such store will get a number of such individuals that

${ }^{17} \mathrm{It}$ is easy to construct numerical examples satisfying (A1) and (A2). Thus, if $E=0$, $x=1$, and $c=1$, there exists an equilibrium with $p_{1}=11 / 8, p_{2}=10 / 8, \hat{s}=2 / 3 \times 1 / 8=$ $1 / 12, f(\hat{s})=18 / 5$, and $F(\hat{s})=1 / 10$. It should be noted that, in constructing this example, only local properties of the search cost distribution have played a role, in particular, $f(\hat{s})$ and $F(\hat{s})$. Hence, the analysis applies equally to the case of $f(0)=0$. 
is proportional to $f(s) / G(p)$. The total sales at any store, then, are proportional to

$$
\int_{\hat{s}(p)}^{\infty} \frac{f(s)}{G(\hat{p}(s))} d s,
$$

where $\hat{s}(p)$ is the search cost of the individual for whom $p$ is the reservation price. We require then that

$$
\pi=p \int_{\hat{s}(p)}^{\infty} \frac{f(s)}{G(\hat{p}(s))} d s=\kappa, \text { a constant },
$$

for all prices in the distribution and

$$
\pi=p \int_{\hat{s}(p)}^{\infty} \frac{f(s)}{G(p(s))} d s \leq \kappa
$$

for all other prices.

Integrating (B 1) by parts, we get

$$
\begin{aligned}
s & =\hat{p} G(\hat{p})+\int_{0}^{\hat{p}} G(p) d p-\left.p G\right|_{0} ^{\hat{p}} \\
& =\int_{0}^{\hat{p}} G(p) d p \equiv H(\hat{p})
\end{aligned}
$$

and

$$
\frac{d s}{d \hat{p}}=G(\hat{p})=H^{\prime} \equiv h(\hat{p}) .
$$

Thus we can rewrite (B3) as

$$
\pi=p \int_{p}^{p_{\max }} f(s(p)) d p+\left[1-F\left(s\left(p_{\max }\right)\right)\right] p
$$

and

$$
\begin{aligned}
\left.\frac{d \pi}{d p}\right|_{\hat{p}} & =\int_{s(\hat{p})}^{\infty} \frac{f}{G} d s-\frac{\hat{p} f}{G} \frac{d \hat{s}}{d p} \\
& =\frac{\kappa}{\hat{p}}-\hat{p} f=0 .
\end{aligned}
$$

Hence

$$
\hat{p}^{2}=\frac{\kappa}{f(\hat{s})}
$$

Using this with (B5) gives the condition

$$
1=F\left(s\left(p_{\max }\right)\right)+\frac{\kappa}{p_{\max }} .
$$


Since, from $(\mathrm{B} 6)$,

$$
\begin{aligned}
\frac{d s}{d p} & =-\frac{2 f}{f^{\prime} p}=G>0, \quad f^{\prime}<0, \\
\frac{d^{2} s}{d p^{2}} & =\frac{2 f}{f^{\prime} p^{2}}+\left(\frac{2}{p}-\frac{2 f}{f^{2}} \frac{f^{\prime \prime}}{p}\right) \frac{2 f}{f^{\prime} p} \\
& =\frac{2 f}{f^{\prime} p^{2}}\left(3-\frac{2 f}{f^{\prime 2}} f^{\prime \prime}\right)=g>0,
\end{aligned}
$$

where $g=d G / d(p)$, so for there to be an equilibrium price distribution

$$
f^{\prime}<0, \frac{f f^{\prime \prime}}{f^{\prime 2}}>\frac{3}{2}
$$

To construct examples satisfying these conditions, set

$$
\frac{f^{\prime \prime} f}{f^{\prime 2}}=m>\frac{3}{2}
$$

Integrating, we get

$$
f(s)=(b+a s)^{1 /(1-m)} .
$$

Integrating again, we obtain

$$
F(s)=(m-1)\left[\frac{(b+a s)^{(m-2) /(m-1)}-b^{(m-2) /(m-1)}}{a(m-2)}\right] .
$$

Substituting into (B6) and inverting, we obtain, say for $1 \leq p \leq u$,

$$
s(p)=\frac{\left(\kappa / p^{2}\right)^{1-m}-b}{a},
$$

with the condition $s(1)=0$ implying

$$
b=\kappa^{1-m} .
$$

From $\left(B 4^{\prime}\right)$ we obtain

$$
G(p)=\frac{\kappa^{1-m} 2(m-1) p^{2 m-3}}{a} \text { for } 1 \leq p \leq u,
$$

implying that if $G(u)=1$,

$$
a=\kappa^{1-m} 2(m-1) u^{2 m-3} \text {. }
$$

Rewriting, we get

$$
G(p)=\left(\frac{p}{u}\right)^{2 m-3}
$$

so there is a mass point at $p=1$ with $G(1)=u^{3-2 m}$. Condition (B7) becomes (using the previously derived conditions)

$$
1=\frac{\kappa}{2(m-2)}\left(\frac{1}{u}-u^{3-2 m}\right)+\frac{\kappa}{u}=t(u) .
$$


Since $t(1)=\kappa$ and $t(\infty)=0$ (since $m>3 / 2)$, there exists, for any $m(m>3 / 2$, $m \neq 2$ ) and $\kappa$, a value of $u$ satisfying (B 14). Thus if the parameters of the search density, $a$ and $b$, are chosen to satisfy (B 10) and (B 12), an equilibrium price distribution can be constructed. For instance, let $m=3$ and $\kappa=2$, so

$$
f(s)=\frac{2}{\left(1+4 s u^{3}\right)^{1 / 2}} ;
$$

then there exists an equilibrium price distribution of the form

$$
G(p)=\left(\frac{p}{u}\right)^{3} \text { for } 1 \leq p \leq u .
$$

In general, the maximum price of the distribution is below the monopoly price; for if it is to raise the same revenues as other stores do, then the highest-price store must serve an interval of individuals, that is, all individuals with search costs greater than or equal to $\tilde{s}$. But then there is some group that is indifferent to searching or not, and hence the elasticity of demand of the highest-price store is greater than the elasticity of demand of the individual's demand curve. (The maximum price may be greater or smaller than the symmetric equilibrium price.)

\section{References}

Arrow, Kenneth J., and Rothschild, Michael. "Preliminary Notes on Equilibrium Price Distributions with Limited Information." Working Paper no. 34. Stanford, Calif.: Stanford Univ., Inst. Math. Studies Soc. Sci., 1973.

$\rightarrow$ Axell, Bo. "Search Market Equilibrium." Scandinavian J. Econ. 79, no. 1 (1977): 20-40.

$\rightarrow$ Braverman, Avishay. "Consumer Search and Alternative Market Equilibria." Rev. Econ. Studies 47 (April 1980): 487-502.

$\rightarrow$ Braverman, Avishay, and Dixit, Avinash. "Consumer Search and Market Equilibria: A Note." Rev. Econ. Studies 48 (October 1981): 657-58.

$\rightarrow$ Butters, Gerard R. "Equilibrium Distributions of Sales and Advertising Prices." Rev. Econ. Studies 44 (October 1977): 465-91.

Diamond, Peter A. "A Model of Price Adjustment." J. Econ. Theory 3 (June 1971): 156-68.

$\rightarrow$ Pauly, Mark V., and Satterthwaite, Mark A. "The Pricing of Primary Ciare Physicians' Services: A Test of the Role of Consumer Information." Bell J. Econ. 12 (Autumn 1981): 488-506.

$\rightarrow$ Reinganum, Jennifer F. "A Simple Model of Equilibrium Price Dispersion." J.P.E. 87 (August 1979): $851-58$.

$\rightarrow$ Rosenthal, Robert W. "A Model in Which an Increase in the Number of Sellers Leads to a Higher Price." Econometrica 48 (September 1980): 157579.

$\longrightarrow$ "A Iynamic Oligopoly Game with Lags in Demand: More on the Monotonicity of Price in the Number of Sellers." Internat. Econ. Rev. 23 (June 1982): 353-60.

$\rightarrow$ Rothschild, Michael. "Models of Market Organization with Imperfect Information: A Survey." J.P.E. 81 (November/December 1973): 1283-1308.

Salop, Steven C. "Information and Monopolistic Competition." A.E.R. Papers and Proc. 66 (May 1976): 240-45. 
"Second-best Policies in Imperfect Competition: How Improved Information May Lower Welfare." Discussion Paper no. 11. Philadelphia: Univ. Pennsylvania, Center Study Organization Innovation, August 1979. Salop, Steven C., and Stiglitz, Joseph E. "Bargains and Ripoffs: A Model of Monopolistically Competitive Price Dispersion." Rev. Econ. Studies 44 (October 1977): 493-510.

$\longrightarrow \rightarrow$ "The Theory of Sales: A Simple Model of Equilibrium Price Dispersion with Identical Agents." A.E.R. 72 (December 1982): 1121-30.

- "Information, Welfare, and Product Diversity." In Arrow and the Foundations of the Theory of Economic Policy, edited by George R. Feiwel. London: Macmillan, 1987.

$\rightarrow$ Satterthwaite, Mark A. "Consumer Information, Equilibrium Industry Price, and the Number of Sellers." Bell J. Econ. 10 (Autumn 1979): 483-502.

Scitovsky, Tibor. "Ignorance as a Source of Oligopoly Power." A.E.R. Papers and Proc. 40 (May 1950): 48-53.

$\rightarrow$ Stiglitz, Joseph E. "Equilibrium in Product Markets with Imperfect Information." A.E.R. Papers and Proc. 69 (May 1979): 339-45. 595-618.

$\rightarrow$ Stigler, George J. "The Economics of Information." J.P.E. 69 (June 1961): 213-25.

von zur Muehlen, Peter. "Monopolistic Competition and Sequential Search." J. Econ. Dynamics and Control 2 (August 1980): 257-81. 